\title{
Relationships between the West Asian subtropical westerly jet and summer precipitation in northern Xinjiang
}

\author{
Yong Zhao • MinZhong Wang • AnNing Huang • \\ HongJun Li • Wen Huo • Qing Yang
}

Received: 6 November 2012 / Accepted: 10 June 2013 / Published online: 12 July 2013

(C) The Author(s) 2013. This article is published with open access at Springerlink.com

\begin{abstract}
The relation between the spatial and temporal variations of the West Asian subtropical westerly jet (WASWJ) and the summer precipitation in northern Xinjiang has been explored using the NCEP/NCAR reanalysis data and the summer precipitation data at 43 stations in northern Xinjiang during 1961 to 2007. Results show that the position of the WASWJ is more important than its strength in influencing the summer precipitation in northern Xinjiang. When the jet position is further south, the anomalous southwesterly flow crossing the Indian subcontinent along the southern foothill of the Tibetan Plateau is favorable for the southwestward warm and wet air penetrating from low latitudes into Central Asia and northern Xinjiang and more rainfall formation. Further analysis shows that the interannual variations of the jet position are well correlated with the Arctic Oscillation (AO). In the weak AO years, the middle to upper troposphere becomes colder than normal and results in an anomalous cyclonic circulation at $200 \mathrm{hPa}$ over Western and Central Asia, which enhances the westerly wind over middle and low latitudes and leads to the WASWJ located further south.
\end{abstract}

\section{Introduction}

In recent decades, changes in mean precipitation across many regions have been documented (IPCC 2007). Xinjiang is located in northwest China, where the interannual and

\author{
Y. Zhao $(\bowtie) \cdot$ M. Wang $\cdot$ H. Li $\cdot$ W. Huo $\cdot$ Q. Yang \\ Institute of Desert Meteorology, \\ China Meteorological Administration, \\ Urumqi, Xinjiang, China \\ e-mail: zhaoyong@idm.cn \\ A. Huang \\ School of Atmospheric Sciences, \\ Nanjing University, Nanjing, Jiangsu, China
}

interdecadal variation of precipitation has some different features from the ones observed in eastern China which is dominated by the East Asian monsoon climate. For example, observational studies indicated that significant changes in precipitation over Xinjiang (eastern China) occurred in late 1980s (1970s) (Shi et al. 2003; Zhou and Huang 2003). In the recent 20 years, the precipitation in Xinjiang has shown an upward trend (Mao et al. 2006; Zhao et al. 2010). Nevertheless, the reason for such an increase is still unclear. For instance, Zhang et al. (2002) argued that it was related to the expansion of oases and farm irrigation. While, Yang and Zhang (2007) attributed it to the anomalous atmospheric circulation patterns with a low-pressure system with quasi barotropic structure sustaining over Central Asia.

In the current study, we further examine the atmospheric circulation patterns influencing precipitation variation in northern Xinjiang, with a particular interest in exploring the linkage between circulation systems over middle and low latitudes. The subtropical westerly jet over the northern hemisphere is an important planetary scale atmospheric circulation pattern in the upper troposphere. It is one of the critical systems influencing the weather and climate in China and the Asian-Pacific regions, with three active centers over Asia (the Caspian Sea, Tibetan Plateau $\left(80-100^{\circ}\right.$ E) and the Asian-Pacific regions) in summer (Yang et al. 2008a; Schiemann et al. 2009). A large number of studies showed that the seasonal transition of the atmospheric circulation over East Asia, including the onset/retreat of the Asian monsoon, and the advance of the monsoon rainfall belt had a close relationship with the change in position and strength of the subtropical westerly jet in East Asia (Chen 1957; Ye et al. 1958; Tao et al. 1958; Li et al. 2004; Zhang et al. 2006; Sampe and Xie 2010). Several studies (Yan et al. 1990; Liang et al. 1998; Lu 2003; Du et al. 2009) suggested that after 1980, with the adjustment of the East Asian atmospheric circulation and the southward movement of the subtropical 
Fig. 1 The summer mean rainfall climatology (contour) and the locations of observation stations $(d o t)$ in northern Xinjiang. Shaded areas indicate the terrain height

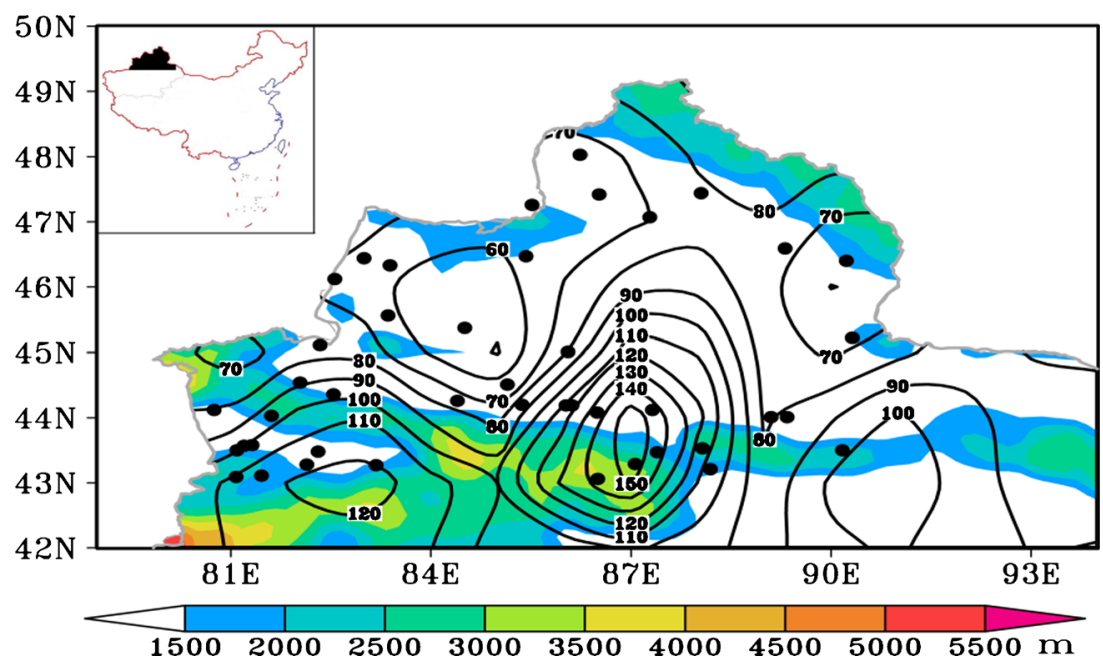

westerly jet, the precipitation in North China decreased significantly, while the precipitation in the Yangtze River basin increased significantly. The intraseasonal anomaly along the subtropical jet induced a change in vertical motion over the Tibetan Plateau and affected the transportation of water vapor to the South Asian monsoon region (Fujinami and Yasunari 2004). Watanabe and Yamazaki (2012) pointed out that the temporary anomaly in the subtropical jet influenced the monsoon over South Asia and Southeast Asia.

Previous studies were more focused on eastern China and Asian-Pacific regions, less attention has been paid to the connection between the subtropical westerly jet and summer precipitation in the arid region. Nevertheless, the northward jump of the subtropical westerly jet in early June occurs not only over the East Asian monsoon regions but also over the West Asian arid regions. The observational studies of Zhang et al. (1986) and Yang et al. (2008b) showed that the position of the West Asian subtropical westerly jet had a close relationship with summer rainfall in Xinjiang, which is attributed to the variations of stationary wave activities along the subtropical westerly jet. As an important atmospheric circulation pattern for summer precipitation in Xinjiang, there are many unanswered questions on the possible mechanisms of the subtropical jet affecting the rainfall in Xinjiang region such as: how the position and strength of the subtropical jet varied and how such variations affected the rainfall over northern
Fig. 2 The first two leading EOF modes of summer zonal wind anomaly at $200 \mathrm{hPa}$ over 25 $55^{\circ} \mathrm{N}$ and $40-80^{\circ} \mathrm{E}$ for $1961-$ 2007 in $\mathbf{a}$ and $\mathbf{b}$. The normalized principal component (PC) corresponding to the leading mode of EOF1 (c) and EOF2 (d). The dashed lines in (c) and (d) indicate $+/-0.5$ standard deviation a

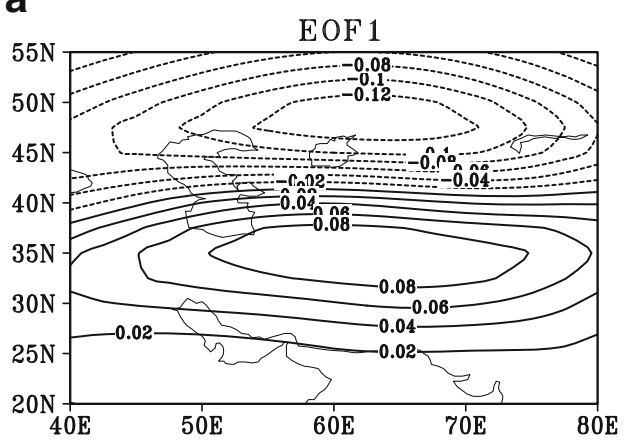

c

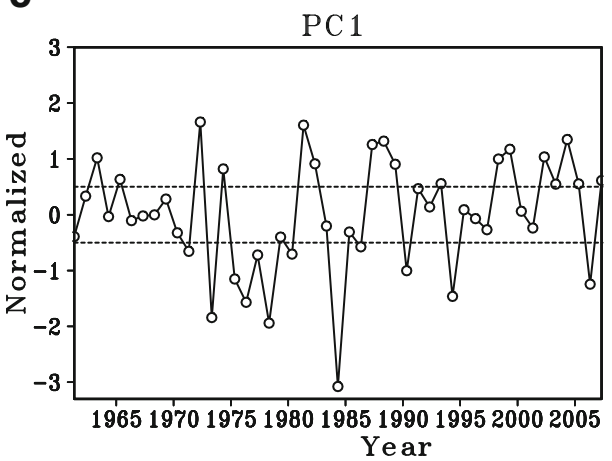

b

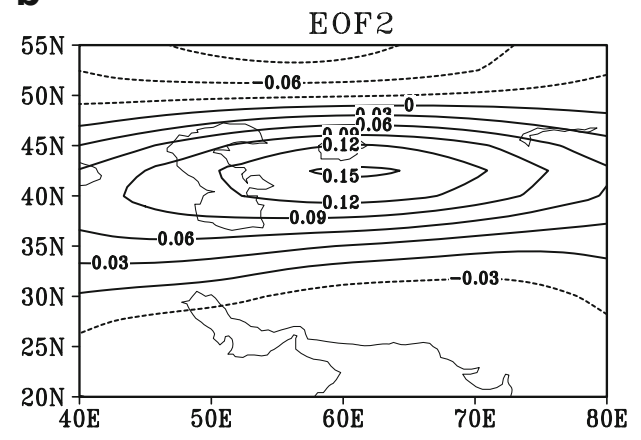

d

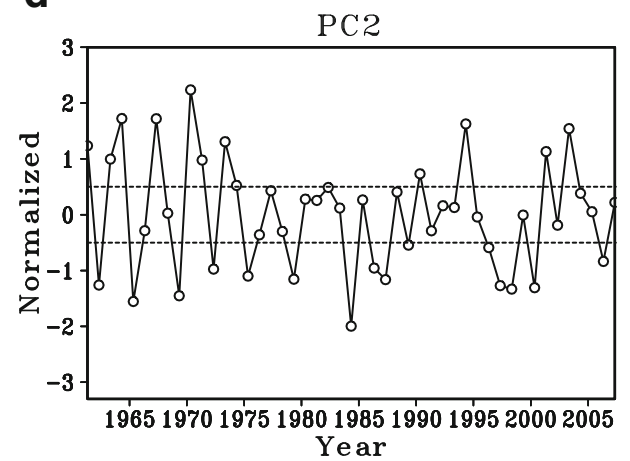



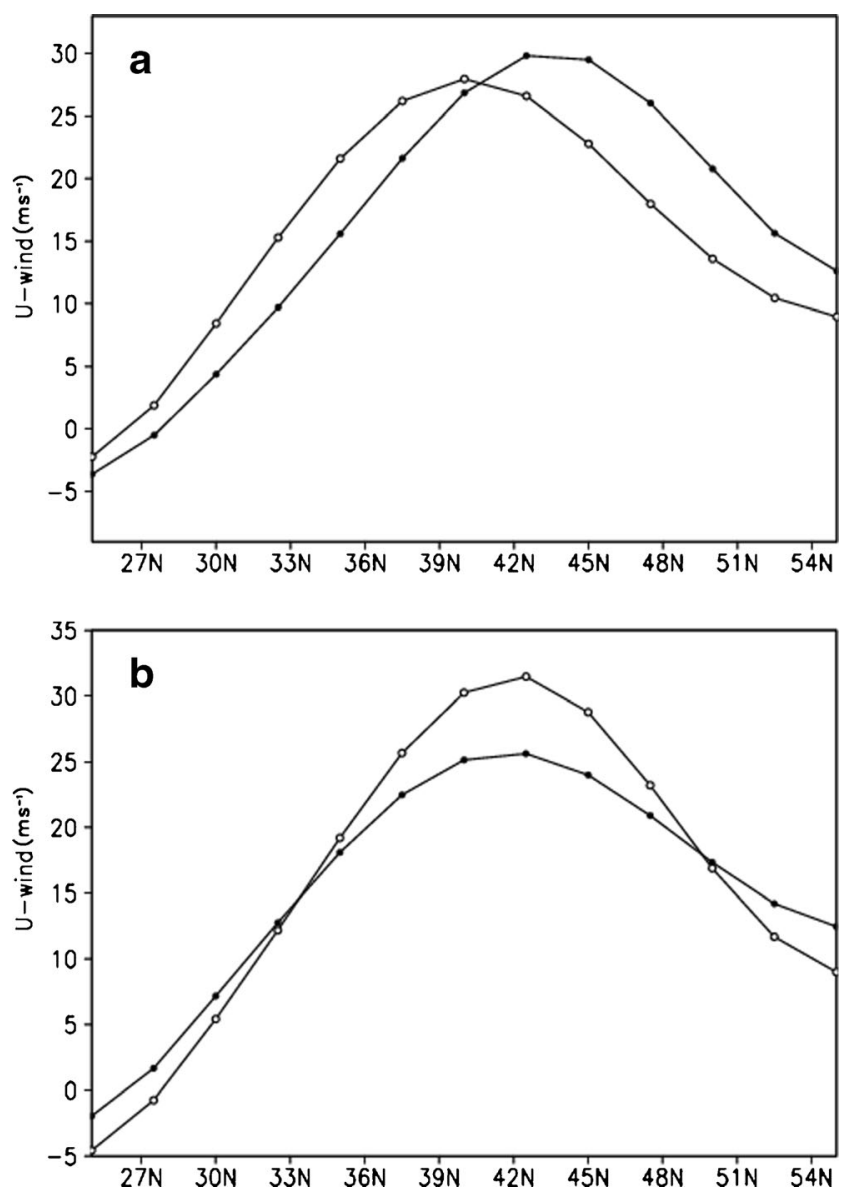

Fig. 3 The meridional distribution of the composite summer zonal wind at $200 \mathrm{hPa}$ averaged along $40-80^{\circ} \mathrm{E}$ for the years with PC1 (a) and PC2 (b) over 0.5 positive standard deviation or below 0.5 negative standard deviation. The open (solid) circle lines indicate the composite means of 200-hPa zonal wind for the years with the PC1 or PC2 over 0.5 positive standard deviation (below 0.5 negative standard deviation)

Xinjiang. We further examined these processes in terms of changes in the atmospheric dynamical and moisture conditions determining the summer rainfall in northern Xinjiang.

The paper is organized as follows: Section 2 gives the study domain, data, and the analytical method. In Section 3, we present the statistical analysis of the connections between the jet position index (JPI) and summer precipitation in northern Xinjiang and explore the possible mechanisms. Finally, main conclusions and discussions are given in Section 4.

\section{Study domain, data, and analytical method}

In recent years, more attention is drawn to study the observed upward trend of summer rainfall in northern Xinjiang (Mao et al. 2006; Zhao et al. 2010). The current study also focuses on northern Xinjiang as shown in Fig. 1, where summer is the major rainy season which accounts for $40-50 \%$ of the annual rainfall (Zhang and Deng 1987). Figure 1 shows the mean summer rainfall together with the observed rainfall stations in northern Xinjiang. It's clear that the summer rainfall in northern Xinjiang shows higher amount in the Tian Shan Mountains than that in the Dzungaria Basin and Altai Mountains. The rainfall dataset at 43 meteorological stations in northern Xinjiang during 1961 to 2007 is provided by the Xinjiang Meteorological Information Center. To assess whether the relocation and instrument changes at some observed stations have contaminated the quality of dataset used in this study (particularly for the trend analysis), the cumulative deviations test (Buishand 1982) is used to reveal the homogeneity of the precipitation data for each station. The results suggest that the precipitation data of the 43 stations are homogeneous over $95 \%$ confident level (not shown).

The National Centers for Environment Prediction/National Center for Atmospheric Research (NCEP/NCAR) reanalysis data (Kalnay et al. 1996) is used to reveal the large-scale atmospheric circulation patterns. In addition, the Arctic Oscillation index (AOI) is derived from the definition of Thompson and Wallace (1998) by applying the Empirical Orthogonal Function (EOF) to the monthly mean sea surface level pressure anomalies poleward of $20^{\circ}$ latitude for the northern hemisphere. All above mentioned data are averaged for the boreal summer months (June, July and August).

The linear correlations are used in this study. The $t$ test (Markham 1979) is used to reveal the significance of the linear correlations as follows:

$t=\sqrt{n-2} \frac{r}{\sqrt{1-r^{2}}}$

Where $r$ is the correlation coefficient between two time series and $n$ is the sample size for the time series.

\section{Results}

3.1 Position and strength of the West Asian subtropical westerly jet

Yang et al. (2008a) found that the summer zonal wind at $200 \mathrm{hPa}$ had several active centers, of which one was located over the region between 40 and $80^{\circ} \mathrm{E}$. Different from the East Asian subtropical westerly jet which has its maximum between 80 and $130^{\circ} \mathrm{E}$, this westerly jet is defined as the West Asian subtropical westerly jet (WASWJ). We use the EOF decomposition to define the position and strength index of the WASWJ.

Figure 2 shows the first two leading EOF modes of the zonal wind anomaly at $200 \mathrm{hPa}$ in the domain of $25-55^{\circ} \mathrm{N}$ and $40-80^{\circ} \mathrm{E}$. The first two leading eigenvectors explain 53.2 and $20.1 \%$ of the total variance, respectively. Thus, more than $70 \%$ of the total variance of the $200-\mathrm{hPa}$ zonal wind anomaly over the region can 

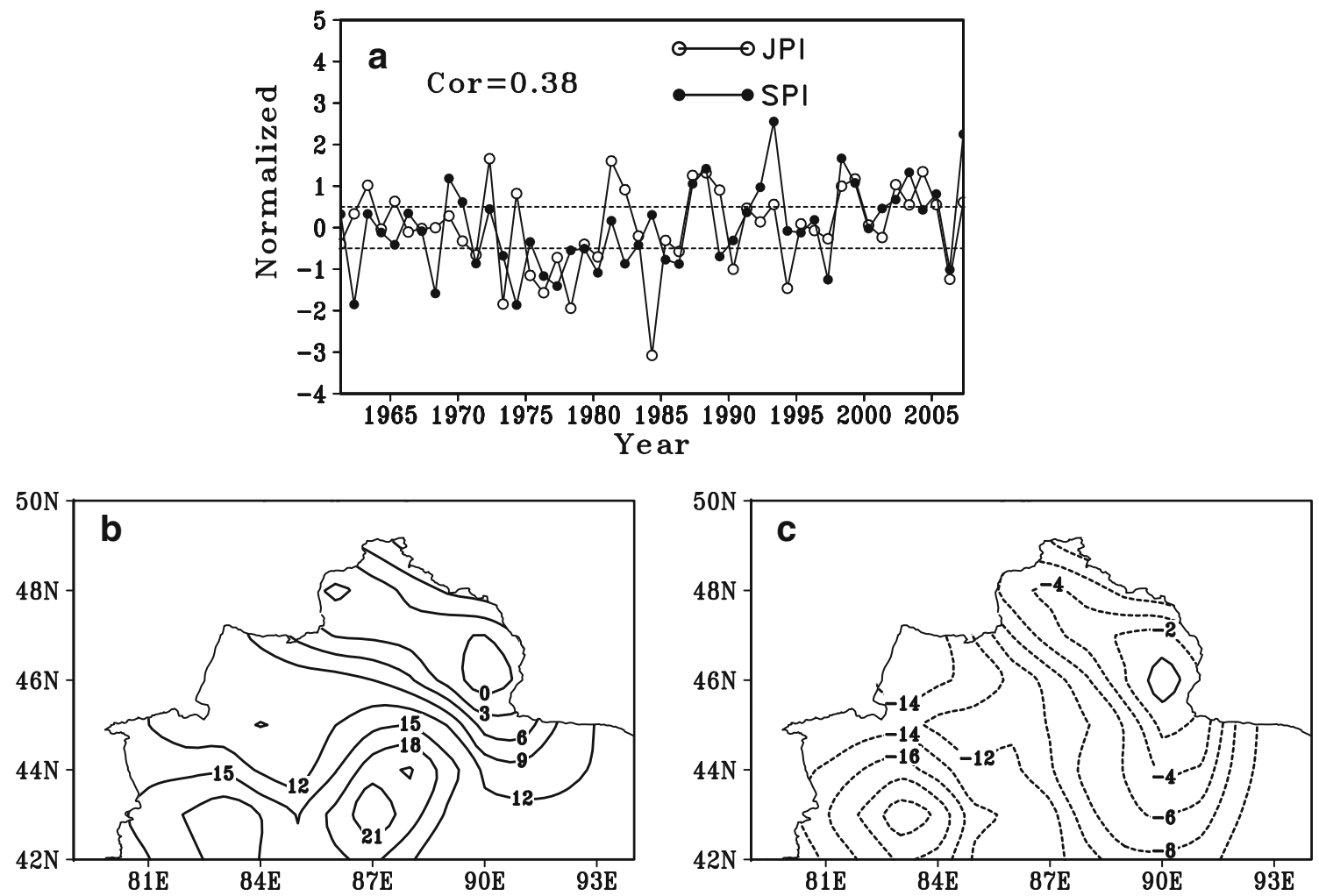

Fig. 4 a The interannual variation of JPI and SPI, the dashed lines indicate $+/-0.5$ standard deviation. The composite of summer precipitation anomalies (unit: $\mathrm{mm}$ ) for the south (b) and the north (c) JPI years

be largely explained by the first two leading EOF modes. The first EOF mode (EOF1) shows a positivenegative distribution from low to high latitudes with the zero line located in $40-42.5^{\circ} \mathrm{N}$ (Fig. 2a). As the mean summer jet axis is located around $40-42.5^{\circ} \mathrm{N}$ (figure not shown), the reverse of the westerly anomalies on both sides of $40-42.5^{\circ} \mathrm{N}$ indicates a meridional migration of the jet axis. The principal component corresponding to the leading mode of EOF1 (PC1) shows significant interannual and interdecadal variations (Fig. 2c). In particular, the jet axis was located further north (south) during 1971 to 1986 (1987 to 2007). The second EOF mode (EOF2) shows a maximum center located over east of the Caspian Sea (Fig. 2b). Its position is co-located over the WASWJ mean position therefore it reflects the variations of the jet strength (Fig. 2d).

We define the years with the normalized PC1 (PC2) exceeding $+/-0.5$ standard deviation as south/north (strong/weak) WASWJ years. Indeed, by averaging the $200-\mathrm{hPa}$ zonal wind over the $40-80^{\circ} \mathrm{E}$ domain over the south/north or strong/weak years, Figures 3a(b) clearly demonstrates that the EOF1 (EOF2) mode of the WASWJ reflects the jet position (strength). The position variations can be as large as three latitudes and zonal wind speed difference between strong and weak years is as large as $5 \mathrm{~m} \mathrm{~s}^{-1}$. Accordingly, the normalized PC1 (PC2) corresponding to the EOF1 (EOF2) mode of WASWJ is defined as the JPI (jet strength index, namely, JSI). In addition, the normalized summer precipitation regionally averaged over the 43 stations in northern Xinjiang is defined as the summer precipitation index (SPI).

\subsection{Relationship between the WASWJ and summer precipitation in northern Xinjiang}

Figure 4a shows that JPI is strongly correlated with SPI over northern Xinjiang with a correlation of 0.38 which is over $95 \%$ of the significant level. However, the JSI is weakly correlated with SPI (figure not shown), suggesting that the WASWJ position is more influential on the summer precipitation in northern Xinjiang than its strength. Thus, we further examine the relationship between the WASWJ position and the summer precipitation in northern Xinjiang in the next sections. The years with the normalized JPI exceeding $+/-0.5$ standard deviation are thought as the south/north JPI years. Accordingly, 17 positive JPI years $(1963,1965,1972,1974$, 1981, 1982, 1987, 1988, 1989, 1993, 1998, 1999, 2002, 2003, 2004, 2005, 2007) and 12 negative years $(1971,1973$, 1975,1976,1977,1978, 1980, 1984, 1986, 1990, 1994, 2006) are chosen as the south and the north JPI years, respectively. Similarly, the years with the moralized SPI exceeding $+/-0.5$ standard deviation are thought as the strong/weak summer 

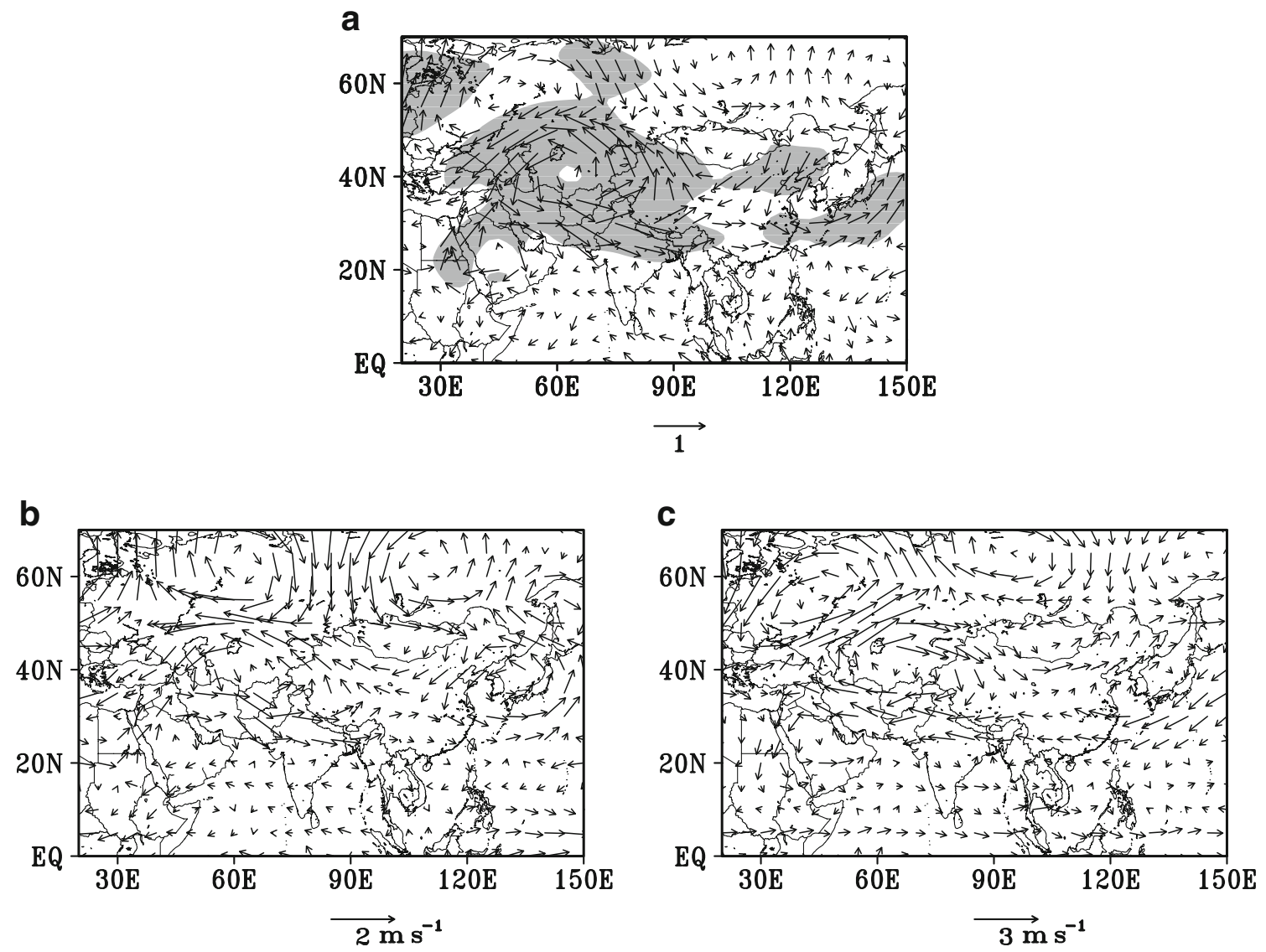

Fig. 5 a The correlation of 500-hPa wind with JPI, the composite of summer wind anomalies at $500 \mathrm{hPa}$ for the south (b) and the north (c) JPI years. Regions over $95 \%$ significant level of $t$ test are shaded

rainfall years, 12 positive SPI years $(1969,1970,1987,1988$, 1992, 1993, 1998, 1999, 2002, 2003, 2005, 2007) and 16 negative SPI years $(1962,1968,1971,1973,1974,1976$, 1977, 1978, 1979, 1980, 1982, 1985, 1986, 1989, 1997, 2006) are chosen as the strong and weak summer rainfall years, respectively. It's clear that 9 of the 12 positive SPI years occurred within the south JPI years. Eight of the 16 weak SPI years occurred in the north JPI years.

In order to illustrate the rainfall distributions in the south and the north JPI years, Fig. $4 \mathrm{~b}$ and $\mathrm{c}$ show the composite mean of summer rainfall anomalies over northern Xinjiang for the south and north JPI years. It can be noted that most of northern Xinjiang are occupied by positive (negative) rainfall anomalies in the south (north) JPI years.

One unclear important question is how the WASWJ position influences the summer precipitation in northern Xinjiang. To answer this question, we further study the impact of the jet position on the regional circulation and moisture transport. Figure 5a gives the correlation of the JPI with the summer 500$\mathrm{hPa}$ wind. It's clearly shown that the JPI variations have considerable influence on the large-scale circulation. Corresponding to the positive JPI (southward shift of the jet position) years, a large cyclonic circulation pattern can be noted in the middle troposphere over Western and Central Asia, with southwestlies and southeastlies prevailing over a large part of Xinjiang. This is confirmed by the composite analysis (Figs. 5b and c). During the south JPI years (Fig. 5b), there is an anomalous cyclone (anticyclone) over Central Asia (Mongolia), resulting in anomalous southerlies prevailing over Xinjiang. This is favorable for the warm and wet air penetrating from the low latitudes to the Xinjiang region and more rainfall generated (Yang and Zhang 2007). On the contrary, during the north JPI years (Fig. 5c), there is an anomalous anticyclone (cyclone) over Central Asia (Mongolia), leading to anomalous northerlies dominating over Xinjiang. This prevents the warm and wet air penetrating from the low latitudes to Xinjiang region and thereafter less rainfall is formed. The anomalous cyclone over Central Asia is one of the key circulation patterns for the summer rainfall occurrence in northern Xinjiang (Zhang et al. 1986; Yang and Zhang 2007).

As shown in Fig. 6a, Xinjiang is located in the far inland region of the Eurasian continent with very limited water vapor supply for the rainfall generation. The correlations between SPI and vertically integrated water vapor in Fig. $6 \mathrm{~b}$ further shows the importance of warm and moist air originated from the low latitudes and transported across the Indian subcontinent and the valley between the Iranian Plateau and foothills of the 

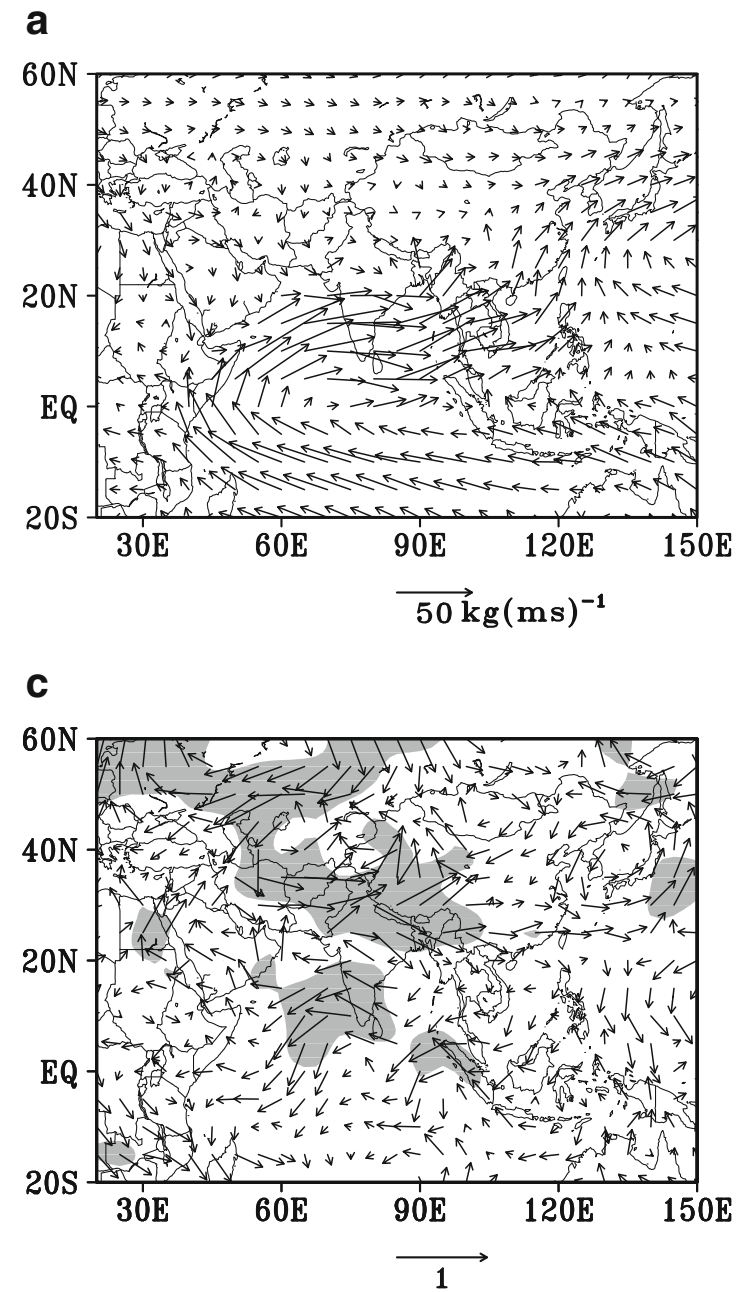

Fig. 6 a The spatial distribution of the summer vertically integrated (surface to $300 \mathrm{hPa}$ ) water vapor flux averaged from 1961 to 2007 . The correlation of SPI (b) and JPI (c) with the vertically integrated water

Tibetan Plateau in influencing the summer rainfall generation over northern Xinjiang. Strong SPI often occurs when there is a cyclonic moisture transport into the northern Xinjiang region. Figure $6 \mathrm{c}$ shows the correlation of the JPI with the vertically integrated water vapor flux (from surface to $300 \mathrm{hPa}$ ). When JPI is positive, there is an enhanced cyclonic moisture transport pattern dominating the Central Asian and most of the Xinjiang region, this shows comparable features with those shown in Fig. 6b, suggesting that the southward shift of the WASWJ provides favorable moisture condition for feeding summer rainfall generation in Xinjiang. Confirmed by the composite analysis (Fig. 6d), an anomalous anticyclonic (cyclonic) circulation can be found over the Indian peninsula (Central Asia) during the south JPI years, which provides favorable circulation conditions for transporting the warm and xmoist air from the tropical ocean into Central Asia and Xinjiang. This is also consistent with previous studies showing that precipitation in Central Asia is derived from tropical moisture sources (Mason and Goddard 2001; Mariotti et al. 2005). b

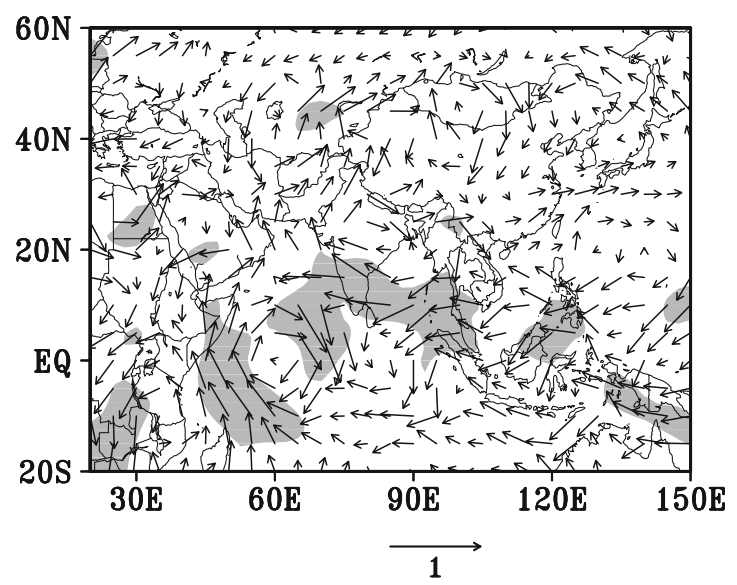

d

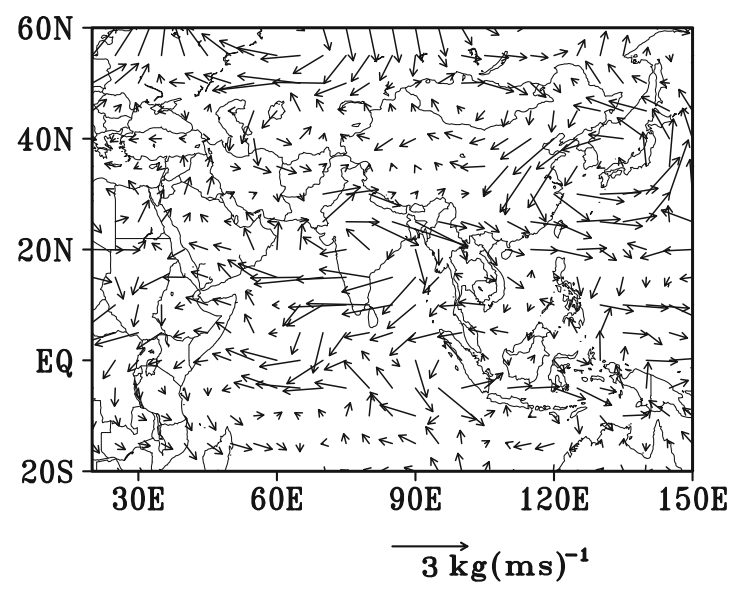

vapor flux (d). The composite mean of the summer vertically integrated water vapor flux anomalies for the south JPI years. Regions over $95 \%$ significant level of $t$ test are shaded in $(\mathbf{b}-\mathbf{c})$

\subsection{Relationship between the Arctic Oscillation and the WASWJ position}

Although the close relation between the WASWJ position and the summer rainfall in northern Xinjiang are identified, what has resulted in the jet position variations is still unclear. The AO is one of the most important large-scale atmospheric circulation patterns over the mid-high latitudes in the northern hemisphere (Thompson and Wallace 1998) and affects the climate in China (Gong and Wang 2003; Li et al. 2008). Hence, the relationship between the WASWJ position and $\mathrm{AO}$ in summer is further studied. As shown in Fig. 7a, the AOI and JPI exhibit a strong correlation of -0.36 which is over $95 \%$ significant level. The correlation coefficient is -0.31 (over $95 \%$ significant level) after removing the linear trend; suggesting that the summer AO has a close relationship with the summer WASWJ position at both interannual and interdecadal time scales. Figure $7 \mathrm{~b}$ shows the correlation of $200-\mathrm{hPa}$ wind and temperature averaged from 700 to 


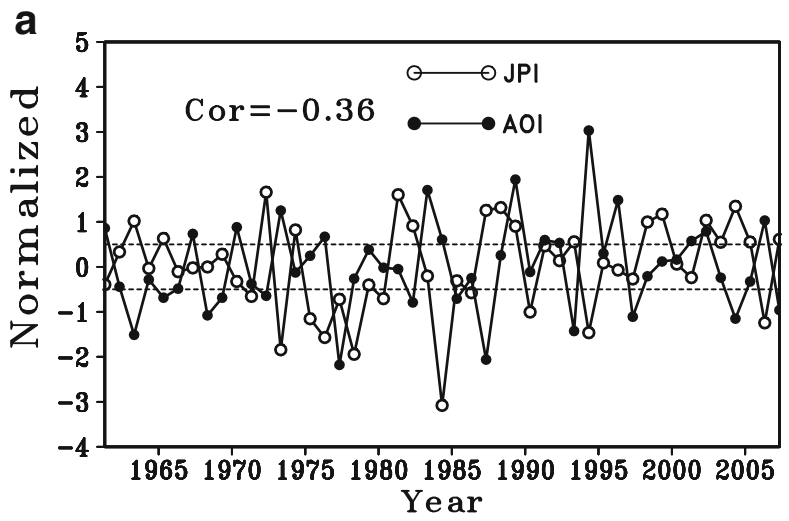

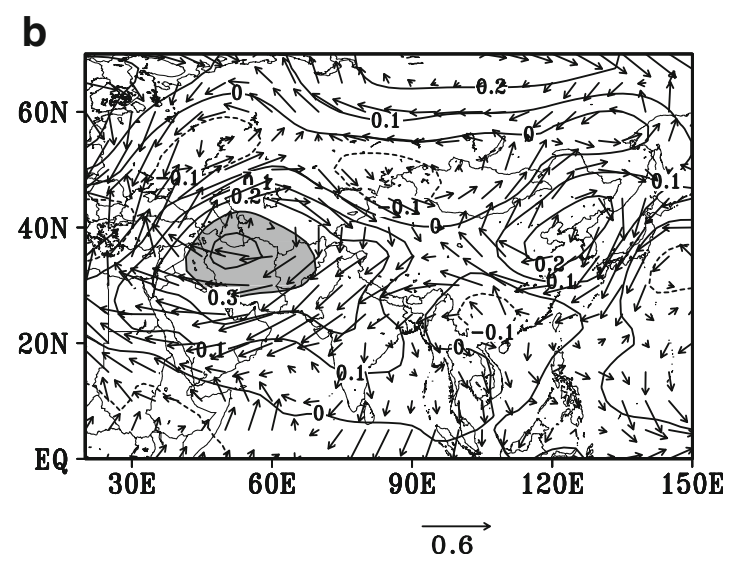

Fig. 7 a The interannual variation of JPI and AOI, the dashed lines indicate $+/-0.5$ standard deviation. $\mathbf{b}$ The correlation of the wind (vector) at $200 \mathrm{hPa}$ and temperature (contour) averaged from 700 to $300 \mathrm{hPa}$ with

$300 \mathrm{hPa}$ with AOI. The middle and upper troposphere over Western and Central Asia becomes colder than normal and is associated with an anomalous cyclonic circulation at $200 \mathrm{hPa}$ during the weak AO years (normalized AOI values exceeding -0.5 standard deviation). This is in good agreement with what is expected from the thermal wind relationship. The strengthened (weakened) 200-hPa zonal winds over the Arabian Peninsula (the Aral Sea and Caspian Sea) lead to a further south WASWJ (Fig. 7c). Previous studies (Yu et al. 2004; Yu et al. 2008) found that in the last 20 years, the further south position of the East Asian subtropical westerly jet was well related to the summer upper troposphere cooling over eastern Asia, and resulted in weakening East Asian summer monsoon and more rainfall over the Yangtze River basin. Current study also suggests that AO has important effects on the middle and upper troposphere temperature over Western and Central Asia.

However, different from East Asian monsoon regions where $\mathrm{AO}$ has a high correlation with eastern Asian summer precipitation (Gong and Ho 2003), only very weak correlation between AOI and summer rainfall in northern Xinjiang can be detected. This suggests that while AO can partially

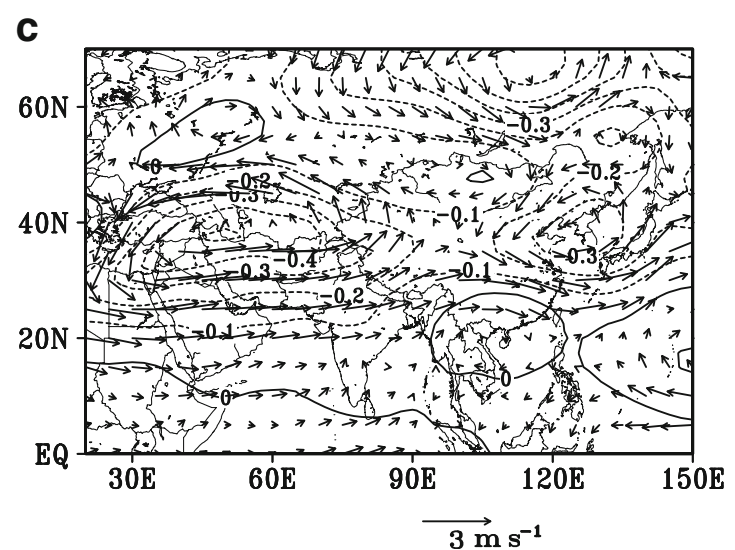

AOI. Regions over $95 \%$ significant level of $t$ test are shaded in (b). $\mathbf{c}$ Composite of 200-hPa wind anomalies (vector) and temperature anomalies (contour, units : ${ }^{\circ} \mathrm{C}$ ) averaged over the weak AO years

influence the variations of the WASWJ position, it has very limited influence on rainfall in Xinjiang. To further understand the possible reasons, Fig. 8a displays the correlation of the AOI with the summer 500-hPa wind. Except for a close correlation with the zonal circulation over subtropical region, the correlation is weak and not significant over most of the region. There is no significant signal suggesting the regional circulation pattern dominating the Xinjiang region can be directly influenced by AO. Figure $8 \mathrm{~b}$ shows the effects of AOI on water vapor transport. The AOI is well related to the anomalous circulation over Indian peninsula and Somali jet, but there is no discernible signal in Western and Central Asian and Xinjiang regions.

As mentioned above, though $\mathrm{AO}$ is one of the most important climate drivers of the climate in the middle and high latitudes of the northern hemisphere, it has limited influences on the regional circulation and water vapor transport which are important for the summer rainfall in northern Xinjiang. The WASWJ plays a critical role in linking the middle latitude systems with the ones from low latitudes. AO is only one of the factors contributing to the jet position variations and yet there are other factors which need to be further explored. 


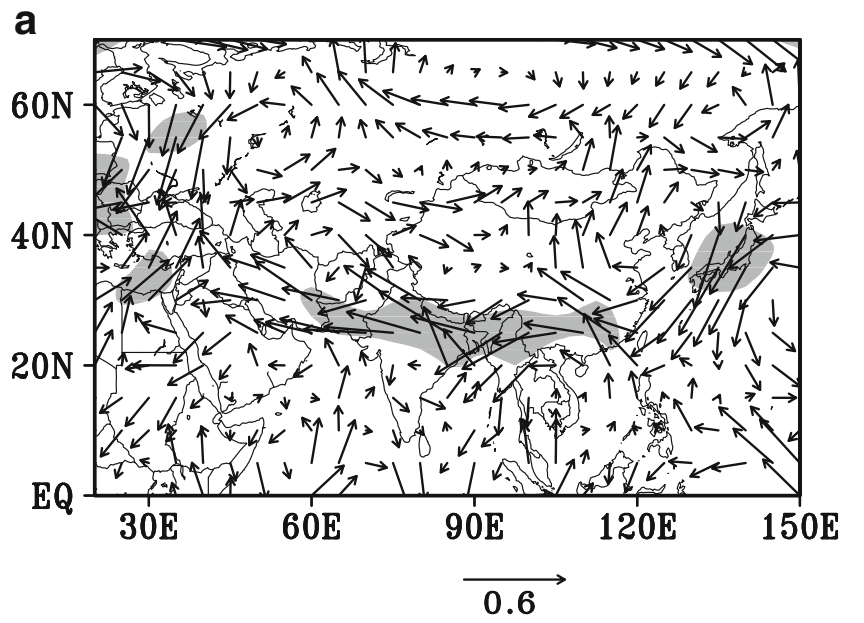

b

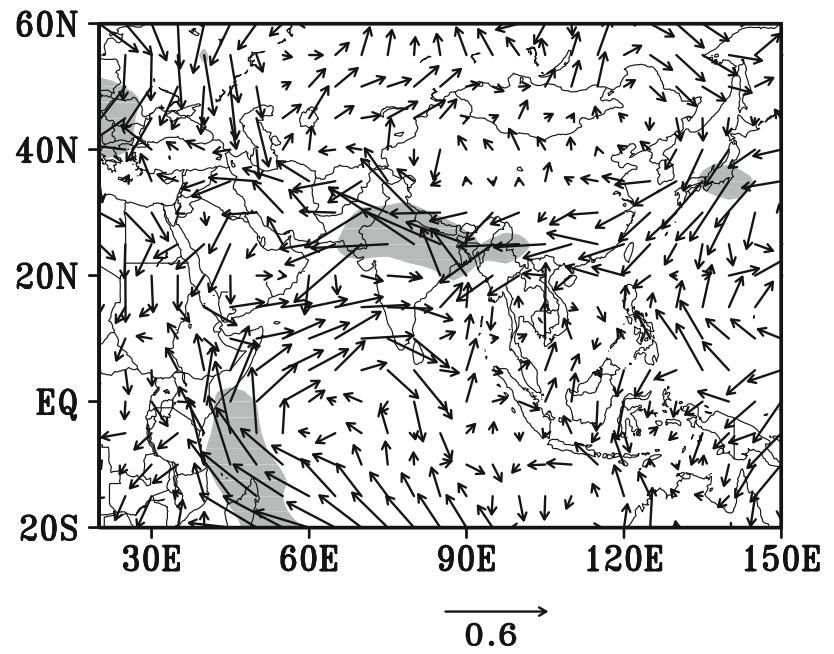

Fig. 8 The correlation of the summer wind vector at $500 \mathrm{hPa}$ (a) and the summer vertically integrated (surface to $300 \mathrm{hPa}$ ) water vapor flux (b) with AOI. Regions over $95 \%$ significant level of $t$ test are shaded

\section{Conclusions and discussions}

Previous studies have identified an increase of summer rainfall over Xinjiang in recent decades (Mao et al. 2006; Zhao et al. 2010), but there is not enough understanding on the processes responding to such an increase. Zhang et al. (2002) attributed it to local land-use change but Yang and Zhang (2007) related it to persistent anomalous atmospheric circulation over Central Asia. In this study, using the NCEP/NCAR reanalysis data (Kalnay et al. 1996) and the summer precipitation data at 43 stations in northern Xinjiang during 1961 to 2007, we have examined the relationship between the WASWJ and the summer rainfall over northern Xinjiang. The mechanism behind this is that warm and moist air from low latitudes is a critical condition for rainfall generation over Xinjiang which is dominated by arid climate. The WASWJ appears to be a primary candidate, which can link the low-latitude systems to the middle latitudes (Ding and Wang 2007).
We have defined a jet position index and a jet strength index to describe the variations of the WASWJ using EOF analysis. Results indicate that WASWJ position shows more significant correlation with the summer precipitation in northern Xinjiang than its intensity. When the WASWJ is located further south, an anomalous cyclone (anticyclone) circulation is located over Central Asia (Mongolia). The corresponding anomalous southerlies prevails over Xinjiang which is favorable for the southwest warm and moist air penetrating from the low latitudes into the Xinjiang region (Yang and Zhang 2007).

Further analysis shows that AO can affect the position of the WASWJ in summer, with a correlation coefficient of -0.36 . During the weak AO years, the middle and upper troposphere over Western and Central Asia becomes colder than normal and is associated with an anomalous cyclonic circulation at $200 \mathrm{hPa}$, which strengthens the west wind over middle and low latitudes, resulting in a further south WASWJ. Despite of the fact that the AO had a close correlation with the summer precipitation in East Asia (Gong et al. 2002), current study suggests that $\mathrm{AO}$ has no direct impacts on summer rainfall over northern Xinjiang. The difference in the relationship of AO and summer rainfall between East Asia and northern Xinjiang is related to the different circulation and water vapor conditions. In East Asia, the summer monsoon supplying plentiful water vapor and the cold air from high latitudes play important roles in precipitation generation in the monsoon region (Tao et al. 1998; Yao and Yu 2005). In contrast, because the northern Xinjiang is located in mid-high latitude inland arid region, its rainfall variations are more dependent on the water vapor supply (Zhang and Deng 1987; Yang and Zhang 2007) and can be significantly modulated by the WASWJ position, which is affected by many factors including AO.

There are yet a few other issues which have not been adequately addressed in this study. For instance, in the current analysis, we have only examined the statistical relationship between WASWJ and summer rainfall variation over northern Xinjiang. Further numerical studies are needed to investigate the synoptic systems dominating over Xinjiang region responding to anomalous WASWJ variations, and quantify the moisture contribution from the low latitudes against other moist sources. In addition, here, we have only studied the possible impacts of AO on the WASWJ position which could only explain a limited part of the variations of the jet position. There are other factors such as the thermodynamic anomalies over the Tibetan Plateau and the land-sea thermal contrast which are also important in influencing the WASWJ variation ( $\mathrm{Li}$ et al. 2004; Kuang and Zhang 2006). All of these need to be considered in future studies.

Acknowledgments We are grateful to NCEP/NCAR for allowing us to use the reanalysis data. We also thank two anonymous reviewers for providing constructive comments that helped improve the original manuscript. We acknowledge the support by the National Basic Research Program of China (973 Program) under Grant no. 2010CB951001 and Nation Science Foundation of China under Grant no.41005050, 41005047. 
Open Access This article is distributed under the terms of the Creative Commons Attribution License which permits any use, distribution, and reproduction in any medium, provided the original author(s) and the source are credited.

\section{References}

Buishand TA (1982) Some methods for testing the homogeneity of rainfall records. J Hydrol 58:11-27

Chen LX (1957) The variation of wind field along $140^{\circ} \mathrm{E}$ at the end of Meiyu. Acta Meteor Sin 28(4):294-302

Ding Q, Wang B (2007) Intra-seasonal teleconnection between the summer Eurasian wave train and the Indian Monsoon. J Climate 20:3751-3767

Du Y, Zhang YC, Xie ZQ (2009) Location variation of the East Asia subtropical westerly jet and its effects on the summer precipitation anomaly over eastern China. Chin J Atmos Sci 33(3):581-592

Fujinami H, Yasunari T (2004) Submonthly variability of convection and circulation over and around Tibetan Plateau during the boreal summer. J Meteor Sci 82:1545-1564

Gong DY, Ho C-H (2003) Arctic oscillation signals in the East Asian summer monsoon. J Geophys Res 108(D2):4066. doi:10.1029/ 2002JD002193

Gong DY, Wang SW (2003) Influence of Arctic Oscillation on winter climate over China. Acta Geogr Sin 58(4):559-568

Gong DY, Zhu JH, Wang SW (2002) The significant correlation between summer precipitation in Yangtze River Basin and the preceding winter Arctic Oscillation. Chin Sci Bull 47(7):546-549

IPCC (2007) Climate Change 2007: The Physical Science Basis. Contribution of Working Group I to the Fourth Assessment Report of the Intergovernmental Panel on Climate Change. In: Solomon S, Qin D, Manning M, Chen Z, Marquis M, Averyt KB, Tignor M, Miller HL (eds). Cambridge University Press, NY, p 996

Kalnay E, Kanamitsu M, Kister R et al (1996) The NCEP/NCAR 40year reanalysis project. Bull Amer Meteor Soc 77:437-471

Kuang XY, Zhang YC (2006) The seasonal variation of the East Asian subtropical westerly jet and its thermal mechanism. Acta Meteor Sin 64(5):564-575

Li CY, Wang ZT, Lin SZ et al (2004) The relationship between East Asian summer monsoon activity and northward jump of the upper westerly jet location. Chin J Atmos Sci 28(5):641-658

Li CY, Gu W, Pan J (2008) Mei-yu, Arctic Oscillation stratospheric circulation anomalies. Chin J Geophys 51(6):1632-1641

Liang XZ, Wang WC (1998) Association between China monsoon rainfall and tropospheric jets. Q J R Meteor Soc 124(6):2597-2623

Lu RY (2003) The line-relation of inter-decadal and inter-annual variations of rainfall in north China. Chin Sci Bull 48(7):718-722

Mao WY, Jiang YA, Li JF (2006) Analysis on the linear tendency of precipitation in Northern Xinjiang. J Glaciol and Geocryol 29(6):797-802

Mariotti AJ, Ballabrera P, Zeng N (2005) Tropical influence on EuroAsian autumn rainfall variability. Climate Dyn 24(5):511-521

Markham CG (1979) Pacific December sea surface temperatures and spring rains in California. J Appl Meteor 18:1369-1370

Mason SJ, Goddard L (2001) Probabilistic precipitation anomalies associated with ENSO. Bull Amer Meteor Soc 82(4):619-638
Sampe T, Xie SP (2010) Large-scale dynamics of the Meiyu-Baiu rainband: Environmental forcing by the westerly jet. J Climate 23:113-134

Schiemann R, Lüthi D, Schär C (2009) Seasonality and inter-annual variability of the westerly jet in the Tibetan Plateau region. J Climate 22:2940-2957

Shi YF, Shen YP, Li DL et al (2003) Discussion on the present climate change from warm-day to warm-wet in northeast China. Chin Quat Sci 23(2):152-164

Tao SY, Zhao YJ, Chen XM (1958) The relationship between Meiyu in far east and the behavior of circulation over Asian. Acta Meteor Sin 29(2):119-134

Tao SY, Zhao YJ, Chen XM (1998) Mei-yu over China. East Asian monsoon and heavy rain in China - celebration of the 80th birthday of Academician Tao Shiyan. Meteorological Press, China, Beijing, pp 3-48

Thompson DWJ, Wallace JM (1998) The Arctic Oscillation signature in the wintertime geopotential height and temperature fields. Geophys Res Lett 25(9):1297-1300

Watanabe T, Yamazaki K (2012) Influence of the anticyclonic anomaly in the subtropical jet over the western Tibetan Plateau on the intraseasonal variability of the summer Asian monsoon in early summer. J Climate 25(4):1291-1303

Yan ZW, Ji JJ, Ye DZ (1990) Northern hemispheric climate jump in the 1960s I. Precipitation and surface air temperature variations. Chin Sci 33:97-103

Yang LM, Zhang QY (2007) Circulation characteristics of interannual and interdecandal anomalies of summer rainfall in northern Xinjiang. Chin J Geophys 50(2):412-419

Yang LM, Zhang QY (2008a) Climate features of summer Asia subtropical westerly jet stream. Clim Environ Res 13(1):10-20

Yang LM, Zhang QY (2008b) Inter-annual variation of summer precipitation in Xinjiang and Asian subtropical westerly jet stream. Chin J Appl Meteor Sci 19(2):171-179

Yao XP, Yu YB (2005) Activity of dry cold air and its impacts on Meiyu rain during 2003 Mei-yu period. Chin J Atmos Sci 29(6):973-985

Ye DZ, Tao SY, Li MC (1958) The catastrophe of general circulation in June and October. Acta Meteor Sin 29(4):250-263

Yu RC, Wang B, Zhou TJ (2004) Tropospheric cooling and summer monsoon weakening trend over East Asia. Geophys Res Lett 31, L22212. doi:10.1029/2004GL021270

Yu RC, Zhou TJ, Li J et al (2008) Progress in the studies of threedimensional structure of interdecadal climate change over eastern China. Chin J Atmos Sci 32(4):893-905

Zhang JB, Deng ZF (1987) A conspectus of precipitation in Xinjiang. BeiJing, Meteorological Press, China, pp 113-117

Zhang JB, Shi YG (2002) The study on climate change and short-term climate prediction in Xinjiang. Beijing, China Meteorological Press, China, p 234

Zhang JB, Su QY, Sun SQ, Zhang JB, Su QY, Sun SQ et al (1986) The guiding manual of short-range weather forecast in Xinjiang. Xinjiang People's Publishing House, China, Urumqi, pp 24-28

Zhang YC, Kuang XY, Guo WD et al (2006) Seasonal evolution of the upper-tropospheric westerly jet core over East Asia. Geophys Res Lett 33:L11708. doi:10.1029/2006GL026377

Zhao Y, Huang DQ, Guli GN et al (2010) Characteristics analysis of summertime heavy rain in northern Xinjiang. Arid Zone Res 27(5):773-779

Zhou LT, Huang RH (2003) Research on the characteristics of interdecadal variability of summer climate in China and its possible cause. Clim Environ Res 8:275-290 